\title{
Teenage Pregnancy: A Mother’s Perspective
}

Joefel T. Libo-on ${ }^{1}$

Joemar F. Manzo ${ }^{2}$

Orfelina I. Manzo

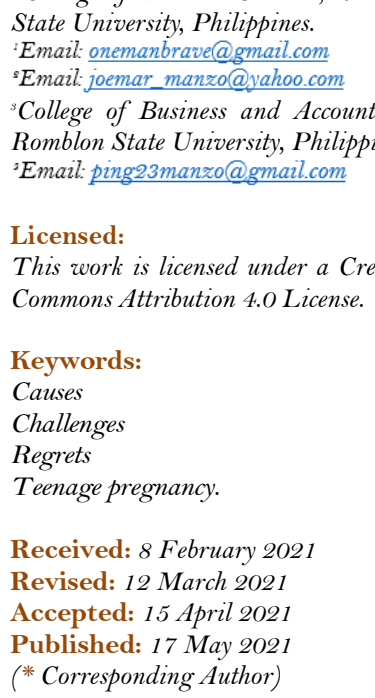

Received: 8 February 2021

Revised: 12 March 2021

Accepted: 15 April 2021

Published: 17 May 2021

(* Corresponding Author)

\begin{abstract}
Teenage pregnancy is a global problem. It confronted all levels of societal status from low, middle to high-income nations. The current paper provides an exploration of the mothers that come across the stage of teenage pregnancy. This provides narratives of the causes, challenges encountered, and their regrets by mothers that come across teenage pregnancy. A qualitative method of research was used in this study. The narrative - case study design was utilized in this methodology. It includes 10 participants and data were gathered through the use of a semi-structured interview schedule. The following were the study's significant findings: The majority of the participants were at the age of 21 and got pregnant at the age of 16-19. Most of them were first-year college students when they got pregnant, unmarried, unemployed, and therefore dependent on their parent's income. Participants' narratives revealed that they got pregnant at an early age because of the individual willingness of having sex with their boyfriend, socialization with their friends, and family influences. It is significantly shown in their narratives that the challenges they encountered in childbearing/raising were financial shortcomings, acceptance of the community, and their marital relationship. Their pregnancy greatly affects their studies resulting in dropping out of school. Participants confronted emotional stress during their pregnancy. Participants commonly narrated that they regretted most finishing their schooling and seeking a quality job.
\end{abstract}

Funding: This study received no specific financial support.

Competing Interests: The authors declare that they have no competing interests.

\section{Introduction}

Teenage pregnancy, also known as adolescent pregnancy, is pregnancy in a female under the age of 20. Pregnancy can occur with sexual intercourse after the start of ovulation, which can be before the first menstrual period but usually occurs after the onset of periods (Steward \& Raja, 2020).

The World Health Organization reported that there are approximately 12 million girls aged 15-19 years and at least 777,000 girls under 15 years give birth each year in developing regions. At least 10 million unintended pregnancies occur each year among adolescent girls aged 15-19 years in the developing world. Complications during pregnancy and childbirth are the leading cause of death for 15-to 19-year-old girls globally. Of the estimated 5.6 million abortions that occur each year among adolescent girls aged 15-19 years, 3.9 million are unsafe, contributing to maternal mortality, morbidity, and lasting health problems (World Health Organization (WHO), 2020).

The UNESCO (2020) releases news stating the Early and Unintended Pregnancy: Recommendations for the education sector, in addition to the detrimental effects on health, social, economic, and education of adolescent girls, early and unintended pregnancy also put the young mother's and the child's lives at risk. Related to pregnancy or childbirth complications are the second leading cause of death among 15- to 19-yearolds, affecting around 70,000 teenagers per year (UNESCO, 2017).

The UNESCO was commissioned to help governments and education actors understand the effects of early and unintended pregnancy and the actions necessary to prevent it while also ensuring that all girls, including those who are pregnant and parenting, can realize their right to education in a safe and supportive 
school environment. In addition to the direct benefit for girls and their families, addressing this pressing problem also contributes to the achievement of several Sustainable Development Goals (SDGs) including Goal 1 is to eradicate poverty; Goal 3 is to promote healthy lives; Goal 5 is to achieve gender equality; and Goal 16 is to create peaceful and inclusive communities (UN Department of Economic and Social Affairs, 2015).

The Philippine Statistics Authority (PSA) estimated that the country will reach a 108.8 million population at the end of 2020. More than 53 million are below 25 years old including the 10.3 million adolescent girls aging 10-19 years old (PSA, 2014). This data shows the potential of the country to accelerate development. On the contrary, the United Nation Population Fund (UNFPA) commissioned a study on 2016 shows that those adolescents in the Philippines who have begun childbearing before the age of 18 are less likely to complete secondary education compared to the adolescents who have not begun childbearing. The noncompletion of secondary education impacts employment opportunities in the future and the total lifetime earnings of families. The net estimated effect of early childbearing due to lost opportunities and foregone earnings can be as high as 33 Billion pesos annual losses for the country (United Nations Population Fund, 2016).

The teenage pregnancy rate in the Philippines was $10 \%$ in 2008 , down to $9 \%$ in 2017 . Live births by teenage mothers (aged 10-19) in 2016 totaled 203,085, which slightly decreased to 196,478 in 2017 and 183,000 in 2018 (UNFPA, 2020). Still, the Philippines has one of the highest adolescent birth rates among the ASEAN Member States. Recent World Bank data shows that the Philippines has 47 births annually per 1,000 women aged 15-19, higher than the average adolescent birth rates of 44 globally and 33.5 in the ASEAN region (UNICEF, 2019). Lao PDR (76), Cambodia (57), Indonesia (48), and Thailand (43). This entails that more than 500 Filipino adolescent girls are getting pregnant and giving birth every day (UNFPA, 2020).

According to the Municipal Social Welfare and Development (MSWD) Office of Odiongan, Romblon, from the year 2015-2019, the number of early pregnancy has also smoothly increased, from the year 2015 the number of teenage pregnancies is 120 while in the year 2016 have some 126, then 105 by the year of 2017,80 in 2018 and 116 in 2019. In five years, the number of cases of teenage pregnancy has a total of 431 in the Municipality of Odiongan. According to the Commission on Population, the gathered data in the said municipality is leading the highest number of early pregnancies in the province of Romblon. This issue is very alarming in the Municipality of Odiongan, Romblon.

\section{Literature Review}

Teenage or adolescence is a stage where teenagers adjust to their physical and emotional changes in life (Steinberg \& Lerner, 2004). World Health Organization (WHO) (2020) described this as a period of development and growth that happens after childhood and before adulthood from ages 10 to 19 . Therefore, teenage pregnancy is defined as a teenage girl, usually within the ages of 13-19, becoming pregnant.

Teenage pregnancy is a social problem that leads to the disruption of schooling, poor child outcomes, childbearing and demographic concerns about increasing population numbers (Macleod, 2003). Smith (2007) identified socio-economic status as the main predictor in understanding teenage mother's educational attainment and long-term low socioeconomic status later in life. Also, many teenage mothers have poor decisions which resulted in severe economic and social consequences. World Health Organization (WHO) (2020) argued that girls who become pregnant before the age of 18 years old are more likely to jeopardize girls' future employment opportunities.

In the study conducted by Navarro and Walker (2012) giving birth by a teenager affects leaving school, and most likely the same will happen to the child of teenage mothers. This conclusion was further strengthened by the finding of Gyan (2013) stating that teenage pregnant dropped out from school for the reason of child delivery or even after delivery, teenage mothers tend not to return to school due to the shy feelings of being pregnant.

Poor maternal and reproductive health is also a prevalent associated with teenage pregnancy as Habitu, Yalew, and Bisetegn (2017) found out that there is high evidence of contraceptive non-use among teenagers which might lead to unwanted and risky pregnancy, and unwanted pregnancy-induced abortions (Aderibigbe et al., 2011). The reasons given for resorting to abortion include; not being married, being too young, still in school, and partners not wanting the child among other reasons (Habitu et al., 2017).

Problematic marital relationship is another issue that teenage mothers are confronting. This argument was supported by the statement of Cummins and Fonseca (2017) saying that teenage pregnancy proceeded to the early marriage unless they were abandoned by the father of the child, in case of rape or if the man was already married. Another consequence of early pregnancy is to go with forced marriage, UNICEF (2001) found out that many of the victims of this practice suffered from prolonged domestic violence, but felt unable to leave the marriage because of economic pressures, lack of family support, and other social circumstances. Domestic violence and divorce is a high possibility of early pregnancy as concluded by Hidayana et al. (2016).

\section{Methodology}

A qualitative method of research was used in this study, hence, non-numerical data were considered in this paper. To explore the narratives of mother-participants on teenage pregnancy, the study utilizes narrative 
analysis. It permits participants to share their experiences in terms of their demographic descriptions; the causes of early pregnancy; problems they encountered as to childbearing, school performance, emotional stress; and their regrets. Informal interviews and discussions through the use of a semi-structured guide question were used to navigate the perspective through conversation among participant's narratives. Narratives of participants were thematically consolidated and analyzed.

Ten (10) mother-participants were interviewed which all came from the Municipality of Odiongan, Province of Romblon. Researchers selected the participants through the use of patanong - tanong, an approach of Indigenous Filipino methodology of Pakapa - kapa (Pe-Pua \& Protacio-Marcelino, 2000). According to Antonio (2016) this method in Philippine Psychology may be defined as a suppositions approach to social scientific investigations. As implied by the term itself, pakapa-kapa is an approach characterized by groping, searching, and probing into an unsystematized mass of social and cultural data to be able to obtain an order, meaning, and directions for research.

Since this study exposes the private life of participants, therefore, the privacy of information was considered. The real name of participants in this study was not mentioned; instead, they were coded as to Key Informant or $\mathrm{K}_{1}$ to $\mathrm{K} 10$. To ascertain the willingness of participants, a letter of consent, approved by the university research office was given and discussed to the participants before the actual conduct of the interviews. The committee on ethics ensures that no participants were harm during the entire conduct of the study. The data gathered where coded, arranged, and analyzed thematically by the researchers.

\section{Results and Discussion}

\subsection{Status of Participants}

During the interview the majority ( 7 or $57 \%$ ) of the participants were already aging 21 years old, 2 among them are 23 years old and one (1) is 19 years old. Also, most or $40 \%$ of the participants got pregnant at the age of $18,30 \%$ of them are 19 years old, $20 \%$ are 17 years old and 1 or $10 \%$ are just 16 years old. Thus, the participants of this study were all teenagers when they were pregnant. In the study of Vieira, Bousquat, Barros, and Alves (2017) these ages were in the age of transition between childhood and adulthood or transition from dependence to independence, this means that at this early age, participants were not matured when they got pregnant and became vulnerable to many of the risk of childbearing.

In terms of the educational attainment of the participants, all of them were college level when they were interviewed. Four (4) or $40 \%$ were second-years, 3 or $30 \%$ were the fourth years, 2 or $20 \%$ were third years and 1 or $10 \%$ is first years. During their conception, $50 \%$ among the participants were just $1^{\text {st }}$-year college students, it is also worth mentioning that $20 \%$ of the participants involved in the study were just in $4^{\text {th }}$-year high school or equivalent to Grade 10 when they got pregnant, and 3 or $30 \%$ were second-year college students. In terms of lag period, four (4) or $40 \%$ continue their studies while they were pregnant. Likewise, $40 \%$ stops their schooling for 3 years, 1 (10\%) stops schooling for 2 years, and the other 1 stops for 4 years. With the difficulties of pregnancy at this early age, the data shows that some of the participants opted to stop their schooling because of their pregnancy. In the interview, the participants narrate the reason for dropping or quitting school. Their reasons were the difficulty of raising their child at the same time going to school $(\mathrm{K} 4)$, they cannot prioritized schooling anymore (K2 and K3), and they cannot manage their child at home after school for they are already tired (K4).

In the study of Darisi (2007) he argued that high performing students had greater motivation to precede their studies only if they have financial capabilities, while low performing students had no interest in going back to school because they believed that they could do better in taking care of their child rather than sending themselves in school and could not support financially in their studies.

\subsection{Causes of Teenage Pregnancy}

Mother's narratives show that the causes of their early pregnancy were their family, their willingness to have sex with their boyfriends, and peer pressure or influences of friends (K9 and K10). Also, participants told that their families were the cause of their early pregnancy by allowing them to live together (K3). Adolescent girls sometimes become rebellious against their parents for being strict in having a boyfriend (K5). On the other hand, $\mathrm{K} 7$ is open to parents to their children in entering into a relationship might also be a cause of early pregnancy.

Mathewos and Mekuria (2018) discussed that teenage pregnancy is more sensitive to family intactness, empirical evidence that family is more important than formal high school education, including sexual education. On the other hand, it further discussed that controlling minor dependency induces reverse causes.

Participants believed that their friends or peers have something to do with their early pregnancy as they meet their boyfriends through friend parties or socialization (K5, K6, and K1). As argued by Pettifor et al. (2004) one of the most powerful psychosocial influences on an adolescent's sexual risk behavior is their peers' perception of the behavior. Furthermore, as children make the transition from childhood to adolescence and engage in the process of identity formation, their reliance on parents and siblings as the sole sources of influence and decision-making begins to change. Adolescents spend more time with friends and peer groups 
than with their parents which can affect their choices and decisions (Gouws, Burger, \& Kruger, 2008; Malisa, 2015).

Individual-level factors influencing teenage pregnancy are described as factors that are most proximal to sexual behaviors and include the teenager's attitude, values, and actions that impinge on his or her sexualrelated choices (Farber, 2009). On the narratives of participants, their willingness and curiosity of having sex with their partners were some of the reasons for getting pregnant (K2, K9, and K10).

\subsection{Teenage Mothers' Encountered Challenges}

Teenage mothers narrate that raising their children shows that they encountered financial challenges in raising their children. According to $\mathrm{K} 2, \mathrm{~K} 5$, and $\mathrm{K} 1 \mathrm{O}$, the needs of the children are more important, additional financial burden was their school expenditures (K9). There were also challenges encountered in giving quality time to their children also the mothers are having difficulties with the discipline of her child (K3). Added to that, there were mothers having problems with their marital relationship with their partners being single mothers $(\mathrm{K} 2, \mathrm{~K} 6)$ and encountered criticisms from the community (K1).

Mangeli, Rayyani, Cheraghi, and Tirgari (2017) have the same findings as they argued that one of the main challenges faced by teenage mothers was ineffectiveness. They lack sufficient knowledge and skills for the successful maternal role and therefore depend on others. Many teenage mothers had a knowledge deficit and their information was not enough to take responsibility for maternal and child care. Teenage mothers showed limited skill with motherhood including prenatal care, breastfeeding, caring for children. Added to that it is evident that they did not receive sufficient support from their husband, families, and health care providers. Teenage mothers expected support from their husbands in all child-related responsibilities and this lack of support from spouses was a bitter experience for teenage mothers. Teen mothers were dependent on others and expected their mothers, other family members, friends, and school training teams to support them in their role as mothers. This lack of support has created problems for the teen in the care and upbringing of the child, child-related costs, continuing education, and community. Health care providers are the most professional source of support for teenage mothers and are expected to meet their educational and care needs.

These arguments of Mangeli et al. (2017). still reflected the mother's pursuit of returning to schools (K3). Mother - participants' narratives show many of the challenges they encountered, as some of them find difficulties in having time for schooling as they were obliged to attend caring for their child (K2, Ks, K4, and K7).

On the other hand, schooling mothers - participants $K 1$ and $K 5$ were confronted with the challenges in their relations to some of their family members and even to their partners or spouse. As to the participants' view on the emotional challenges they encountered, it is narrated by most of the participants that they were feared a miserable life after they got pregnant (K3). They fear that they will not be accepted or of the hatred of their family and other people (K3, K6, K7, and K9).

It is further elaborated by participants $\mathrm{K} 3, \mathrm{~K} 4, \mathrm{~K} 5, \mathrm{~K} 6, \mathrm{~K} 7, \mathrm{~K} 8$, and $\mathrm{K} 9$ in their narratives that many of them tried to hide their pregnancy from their family for some time. This behavior reflects the immaturity or unpreparedness of mothers in this unintended phenomenon. These kinds of behavior of mothers are the reasons their health with their child at their womb were at risk. These were the times that mother supposed to avail health and maternal care services

\subsection{Things the Teenage Mothers Regretted Most}

Teenage mothers regretted most the loss of their opportunity of finishing their schooling (K1, K2, K6, and K10). Losing education according to participants $\mathrm{K} 2, \mathrm{~K} 3, \mathrm{~K} 4, \mathrm{~K} 5, \mathrm{~K} 6, \mathrm{~K} 7$, and K9 follows the loss of the opportunities of getting employment or fulfilling their dreams.

On the other hand, these experiences made a girl a more mature person and ready to face the new stage of their life as they learned lessons from their way as they share their narratives that there is always a right time for being a mother (K1, K3, K5, K4), they have to face the problem instead of running from it (K2), to value our parents and their advice, and to focus on schooling instead of focusing in love life $(\mathrm{K} 7)$.

\section{Conclusion and Recommendations}

Teenagers are potentials of development; on the other hand, it becomes potential losses when girls become a mother at an early age. This is based on the own perspective of teenage mothers that they opted to quit their schooling the same as with the potentials of quality of life through employment. Adolescent mothers who want to continue their schooling may be confronted with different challenges as to time management, finances, or even their marital relationships.

From the narratives of the teenage mothers, it is obvious that their willingness to engage in premarital sex causes their early pregnancy. Family, friends, and other people surrounding teenage girls or mothers are important factors that affect their pregnancy. On the other side, these were also important factors that can prevent teenagers from being pregnant.

After hearing the narratives of teenage mothers, two major recommendations can be drawn from this paper. First, put those neglected players on the right track again to regain their potentials. In this argument, 
the academe will play an important role in guiding these teenagers to their success. The office of Gender Advocacy and Development (GAD) and the guidance counsellors in every school and university should monitor their mother - students. Regular consultation and encouragement are a big help for mothers in correcting their greatest regrets of finishing their studies and in achieving their dreams of quality employment.

Secondly, preventing our players from committing mistakes. Teenage pregnancy can be minimized if not prevented if they will not practice outside wedding sexual practices. On this matter, creating awareness of teenage pregnancy in the community and the academe is a must. There is a need to utilize all the means of information dissemination to reach out to the community at large to raise awareness about the causes and consequences of teenage pregnancy. This can be done through information and educational campaigns in schools, universities, and communities.

Part of creating awareness is to initiate "Parent-Child Communication Workshops" in the communities. There is a great need to improve parent-child communication; therefore workshops can be arranged in schools, universities, or communities. This approach aims to empower parents and their children to develop effective communications strategies so that together they can address the issues that teenagers are confronting including sexual and reproductive health.

\section{References}

Aderibigbe, S. A., Araoye, M. O., Akande, T. M., Musa, O. I., Monehin, J. O., \& Babatunde, O. A. (2011). Teenage pregnancy and prevalence of abortion among in-school adolescents in North Central, Nigeria. Asian Social Science, 7(1), 122. Available at: https://doi.org/10.5539/ass.v7n1p122.

Antonio, C. (2016). A historical account of research in Filipino psychology: Milestones, methods, and ethical issues. Retrieved from https://bit.ly/2XIPWzH.

Cummins, D., \& Fonseca, M. (2017). Teenage pregnancy and early marriage; Research on the decision-making pathways of young women in the municipalities of Covalima, Aileu and Dili (pp. 4). Technical Report. UNFPA in Dili, Timor-Leste.

Darisi, T. (2007). Teen pregnancy prevention: Exploring out of school approaches (pp. 1-10). Technical Report. Ontario's Maternal, Newborn and Early Child Development Resource Centre.

Farber, N. (2009). Adolescent pregnancy: Policy and prevention services (2nd ed., pp. 99-122): Springer Publishing Company.

Gouws, E., Burger, S., \& Kruger, N. (2008). The adolescent. Johannesburg: Heinemann Publishers.

Gyan, C. (2013). The effects of teenage pregnancy on the educational attainment of girls at Chorkor, a suburb of Accra. Journal of Educational and Social Research, 3(3), 53-60.

Habitu, Y., Yalew, A., \& Bisetegn, T. (2017). Prevalence and factors associated with teenage pregnancy, Northeast Ethiopia, 2017: A cross-sectional study. Journal of Pregnancy, 2018, 1-7. Available at: https://doi.org/10.1155/2018/1714527.

Hidayana, I. M., Noor, I. R., Benedicta, G. D., Prahara, H., Zahro, F. A., Kartikawati, S., \& Kok, M. C. (2016). Factors influencing child marriage, teenage pregnancy and female genital mutilation/circumcision in Lombok Barat and Sukabumi Districts, Indonesia (pp. 1-84). Technical Report. December 2016.

Macleod, C. (2003). Teenage pregnancy and the construction of adolescence: Scientific literature in South Africa. Childhood, 10(4), 419-437. Available at: https://doi.org/10.1177/0907568203104003.

Malisa, J. N. (2015). Factors contributing to teenage pregnancies in Tunduru District Council. Doctoral Dissertation, Mzumbe University.

Mangeli, M., Rayyani, M., Cheraghi, M. A., \& Tirgari, B. (2017). Exploring the challenges of adolescent mothers from their life experiences in the transition to motherhood: A qualitative study. Journal of Family and Reproductive Health, 11(3), 165-173.

Mathewos, S., \& Mekuria, A. (2018). Teenage pregnancy and its associated factors among school adolescents of Arba Minch Town, Southern Ethiopia. Ethiopian Journal of Health Sciences, 28(3), 287-298. Available at: https://doi.org/10.4314/ejhs.v28i3.6.

Navarro, P. M., \& Walker, I. (2012). The impact of teenage motherhood on the education and fertility of their children: Evidence for Europe (pp. 4-11). Institute of Labor Economics (IZA). IZA Discussion Paper No. 6995. November 2012.

Pe-Pua, R., \& Protacio-Marcelino, E. A. (2000). Sikolohiyang Pilipino (Filipino psychology): A legacy of Virgilio G. Enriquez. Asian Journal of Social Psychology, 3(1), 49-71. Available at: https://doi.org/10.1111/1467-839x.00054.

Pettifor, A., Rees, H., Kleinschmidt, I., Steffenson, A., MacPhail, C., Hlongwa-Madikizela, L., . . Padian, N. (2004). Young people's sexual health in South Africa: HIV prevalence and sexual behaviors from a nationally representative household survey. AIDS, 19(14), 1525-1534. Available at: 10.1097/01.aids.0000183129.16830.06.

PSA. (2014). A 142 Million Philippine population by 2045? Retrieved from https://psa.gov.ph/content/142-millionphilippine-population-2045.

Smith, B. L. (2007). "I wanna have a good future": Teen mothers' rise in educational aspirations, competing demands, and limited school support. Youth छ Society, 38(3), 348-371. Available at: https://doi.org/10.1177/0044118x06287962.

Steinberg, L., \& Lerner, R. M. (2004). The scientific study of adolescence: A brief history. The Journal of Early Adolescence, 24(1), 45-54. Available at: https://doi.org/10.1177/0272431603260879.

Steward, K., \& Raja, A. (2020). Physiology, ovulation, and basal body temperature. 2020. In: statpearls [Internet]. Treasure Island $(F L)$ : StatPearls Publishing.

UN Department of Economic and Social Affairs. (2015). The 17 goals. Retrieved from https://sdgs.un.org/goals. 
UNESCO. (2017). Education critical in preventing adolescent pregnancy. Retrieved from http://www.unesco.org/new/en/media-services/single-

view/news/education critical in preventing adolescent pregnancy/.

UNESCO. (2020). United nation educational, scientific and cultural organization. Prioritize health and well-being now and when schools reopen. Retrieved from: https://en.unesco.org/news/prioritize-health-and-well-being-now-andwhen-schools-reopen.

UNFPA. (2020). Eliminating teenage pregnancy in the Philippines. Retrieved from https://philippines.unfpa.org/sites/default/files/pubpdf/UNFPA_Policy_Brief_Teenage_Pregnancy_\%282020-01-24\%29.pdf.

UNFPA. (2020). Policy brief, girls not mother. Retrieved from https://philippines.unfpa.org/en/publications/girlsnotmoms-eliminating-teenage-pregnancy-philippines.

UNICEF. (2001). Early marriage child spouses. Retrieved from https://bit.ly/38NWP9g.

UNICEF. (2019). Early childbearing. Retrieved from https://data.unicef.org/topic/child-health/adolescent-health/.

United Nations Population Fund. (2016). P33B in potential income lost due to teen pregnancy. Retrieved from https://philippines.unfpa.org/en/news/p33b-potential-income-lost-due-teen-pregnancy-0.

Vieira, E. M., Bousquat, A., Barros, C. R. d. S., \& Alves, M. C. G. P. (2017). Adolescent pregnancy and transition to adulthood in young users of the SUS. Public Health Journal, 51, 25. Available at: https://doi.org/10.1590/s 15 188787.2017051006528.

World Health Organization (WHO). (2020). Adolescent pregnancy. Retrieved from https://www.who.int/newsroom/fact-sheets/detail/adolescent-pregnancy. 